\title{
Effects of Vision Health Education and Free Eyeglasses on Knowledge of Vision and Usage of Spectacles Among Primary School Students: Evidence from Gansu and Shaanxi Provinces in China
}

This article was published in the following Dove Press journal:

Risk Management and Healthcare Policy

\author{
Yunyun Zhang' \\ Hongyu Guan' \\ Kang Du' \\ Jin Zhao' \\ Yaojiang Shi (DI \\ Huan Wang' \\ Decai Wang ${ }^{2}$
}

'Center for Experimental Economics in Education, Shaanxi Normal University, Xi'an, People's Republic of China;

${ }^{2}$ Zhongshan Ophthalmic Center, State Key Laboratory of Ophthalmology, Sun Yat-Sen University, Guangzhou, People's Republic of China
Correspondence: Hongyu Guan

Center for Experimental Economics for Education, Shaanxi Normal University, Xi'an, 7I0II9, People's Republic of China Tel +86 I86-9188-962I

Email guanhongyu2016@163.com
Background: In rural China, children's vision problems are very common, with many who would benefit from refractive correction not getting the care they need. This study examines whether a health information campaign that involves vision health education and a free trial of health product with free eyeglasses is effective at raising students' awareness of myopia and promoting students' eyeglasses usage.

Methods: We conducted an in-the-field randomized controlled experiment of a program providing vision health education and subsidized free eyeglasses to myopic children from 168 primary schools in rural Northwestern China in 2012.

Results: A total of 2189 students, mean age 10.5 years $(49.3 \%$ male), participated in the baseline survey. At the baseline, the average correct response rate for visual knowledge among the sample students was $30.1 \%$, and only $15 \%$ who needed eyeglasses used them. Seven months after intervention, the average correct response rate for vision knowledge were $48.5 \%$ and $48.3 \%$ in the education group and the education plus free eyeglasses group respectively, significantly higher than that of the control group. The rate of eyeglasses usage was $36 \%$ and $43 \%$ in the free eyeglasses group and the education plus free eyeglasses group respectively, significantly higher than that of the control group. The rate of eyeglasses compliance in the free eyeglasses group and the education plus free eyeglasses group was $19 \%$ and $26 \%$, which also were significantly higher than the control group.

Conclusion: The information campaign combined with subsidized eyeglasses had a better effect both on vision knowledge and eyeglasses usage. The information campaign improved knowledge by providing the right information, and free eyeglasses changed the perceived utility and experience by the students using the product and getting benefits. Information and the free eyeglasses (subsidized) are complements.

Keywords: vision health education, subsidies free eyeglasses, health-seeking knowledge, health-seeking behavior

\section{Introduction}

In rural China, children's vision problems are very common. ${ }^{1-3}$ Several studies have reported that children with refractive errors who have not undergone correction have lower scores on various sports and cognitive tests, ${ }^{4-7}$ and that there are improvements in children's reading ability and academic performance when vision problems are corrected. ${ }^{7}$ 
In most cases, wearing quality eyeglasses at the correct time and properly can easily correct children's vision problems. ${ }^{8}$ Unfortunately, a considerable number of children in rural China who can benefit from refractive correction (through properly prescribed eyeglasses) do not seem to receive corrective services. ${ }^{2,-11}$ Recent surveys conducted in rural China indicate that less than $33 \%$ of students own eyeglasses and even fewer students wear them. ${ }^{12}$ According to the results of a study by Yi et al., only one-sixth of myopic students in rural China use eyeglasses. ${ }^{11}$

Misunderstanding about vision problems and eyeglasses, and underestimation or unawareness of the benefits of wearing eyeglasses lead to low usage rates of eyeglasses in rural China. ${ }^{12-14}$ A common piece of misinformation is that using eyeglasses will further damage the eyesight. Also, despite having no ophthalmological basis or evidence on their efficacy, many still believe that one of the effective ways to prevent and treat myopia is to do eye exercises. ${ }^{15}$ Many students, parents, and teachers do not know what myopia is, how to treat it, and the correlation between vision correction and school performance. $^{2,12,16-18}$

Many recent documents focus on ways to increase adoption of inexpensive, easy-to-run health products such as eyeglasses. There are two commonly proposed methods: information campaigns and provision of high subsidies or distribution of free health products. ${ }^{3,19,20}$ Health education that targets caregivers or beneficiaries has the potential to increase health knowledge, change people's perception, ${ }^{21-24}$ and instill healthy behaviors that help improve health-care uptake. ${ }^{25,26}$ Through provision of a health product for free, individuals reveal the demand for health products due to the learning effect if they benefit from using the product. ${ }^{1,2,27}$

Although many studies have estimated the impact of information campaigns ${ }^{28,29}$ and subsidies ${ }^{17,25,2,12,29-32}$ in isolation, few studies exist that investigate these two programs when implemented at once. Ashraf (2010) found information intervention and subsidies are complementary: by providing consumers with more information about the product, the effectiveness of price subsidies increases by about $60 \% .{ }^{30}$ Dupas (2014) discovered that short-term subsidies combined with information acquisition for ITN (insecticide-treated nets) will increase long-term demand. ${ }^{33}$

These studies, however, focus more on the uptake and behavior itself rather than the acquisition of health knowledge, which is very important to change behavior. ${ }^{28,29}$ Particularly for products such as eyeglasses, antimalarial bed nets, water treatment kits, or condoms, repeat purchases and consistent use are required to generate the hoped-for health impacts. Dupas's research (2014) suggested that a one-time subsidy for a new health product impacts repeat purchases through the effect on knowledge about the products. ${ }^{34}$, The relationship between information campaigns and distribution of free health products is not well studied, especially with empirical method.

The overall goal of this research is to explore the impact of an information campaign and free trial both on the knowledge and the usage of health products in a poor rural area. To meet these objectives, this study draws on data from a field randomized controlled experiment of an intervention that provides eyeglasses prescriptions and eyeglasses subsidy vouchers to children who have vision problems. Ma et al. (2014) reported the main results of the randomized controlled experiment, which examined the impacts of intervention on students' eyeglasses adoption, eyeglasses using, and student academic performance. ${ }^{3}$ We study whether a health education campaign that supplys vision health education and a free trial of eyeglasses is effective at raising students' awareness and understanding of myopia and the benefits of using eyeglasses and at promoting eyeglasses usage.

To that end, this study has two specific goals. First, we seek to understand the vision knowledge and eyeglasses usage in a poor rural area. Second, we conduct econometric analyses to examine the causal impacts of three different interventions on vision knowledge, eyeglasses usage and the daily vision health behavior (eyeglasses compliance).

The framework of the study is organized as follows. The second part introduces the experiment design and data collection. The third part presents the study results. The fourth part discusses the policy implications of the experimental results and draws conclusions.

\section{Methods}

The data we used in this paper was obtained from a vision project implemented in collaboration with Stanford University and Sun Yat-Sen University. Shaanxi Normal University does not set up an Ethics Committee for public health projects, therefore the ethical committee approval for this study was obtained from the Stanford University Institutional Review Board (Registration number: ISRCTN03252665, registration site: http://isrctn.org) and Sun Yat-Sen University (Registration number: 2013MEK Y018). 
This research always adhered to the principles of the Declaration of Helsinki. Permissions were received from the local education committee in the study area and the principals of all sample schools. All the sample students include in the study were verbally questioned and agreed to participate before collecting baseline data, and the legal guardians provided written informed consent for their children to participate in the study.

\section{Sampling}

The data of this study were drawn from an experiment providing free eyeglasses to rural children, which was conducted in Tianshui prefecture of Gansu province and Yulin prefecture of Shaanxi province during the 2012-2013 school year.

We selected sample schools through the following five steps. First, we obtained the list of counties in the two prefectures from the local government. Second, we included all counties in these two prefectures, except for one county in Yulin prefecture (Wubu county is not included because of its small population size.). A total of 18 counties were sampled, including seven counties in Tianshui prefecture and 11 counties in Yulin prefecture. After selecting the sample counties, in the third step we obtained a list of all primary schools from local education bureaus of each county. In all, we included 435 schools in the sample box. In the fourth step, we randomly selected one school from each township of 18 sample counties. We excluded sample schools with fewer than 50 or more than 150 sample students in fourth and fifth grade together. This is because in the larger schools, vision screening cannot be done in one day, which would have interfered with the vision screening schedule, while in the smaller schools, fewer than 15 children would need glasses, which is less than our power requirements for statistical analysis. In the fifth step, in each school, only one class was included in each grade. If there was more than one class in either grade, we randomly selected one class only. Finally, we selected 252 sample schools.

\section{Data Collection}

The baseline survey was conducted in September 2012, including vision screening and questionnaire survey.

\section{Visual Acuity Assessment}

We administered a detailed eye examination on students. A vision screening team composed of two well-trained staff used Early Treatment Diabetic Retinopathy Study eye charts to carry out visual acuity (VA) screening for students. Students who failed the VA screening test (VA of either eye less than or equal to $6 / 12$, or $20 / 40$ ) took another vision test. This vision test was carried out at each school by a team of a professional optometrist, a nurse, and an assistant one or two days after the initial vision test. The test includes automatic refraction and subjective improvement after cycloplegia to determine whether a student is eligible for eyeglasses (the cut-off value for myopia is $\leq-0.5$ diopters [D]). The Zhongshan Ophthalmic Center (ZOC) at Sun Yat-sen University trained the team administering the examination.

\section{Questionnaires}

Questionnaires were distributed to all selected sample students in the fourth and fifth grades, including a vision knowledge questionnaire, student questionnaire and household questionnaire.

The vision knowledge questionnaire was developed and reviewed by a group of health experts from Shaanxi Normal University and Zhongshan Ophthalmic Center, an authoritative ophthalmology institution in China.

The student questionnaire collected information about students' characteristics including age, grade, gender, their knowledge of vision health, whether they owned eyeglasses before, awareness of myopia status, whether boarding at school and whether their parents were at home. In this study, students were left-behind children if their parents were away from home for more than six months each year, and otherwise students were non-leftbehind children. Mathematics tests was also conducted with test questions from projects developed for the Trends in International Mathematics and Science Study.

The household questionnaire was handed out to all students' caregivers. The household questionnaire collected information on parents' level of education and family assets, which may be difficult for children to answer. To estimate the value of family assets, caregivers were asked to answer whether their family have the following assets (based on the "National Household Income and Expenditure Survey", which is organized and published by the National Bureau of Statistics of China): car, van, motorcycle, tractor, agricultural equipment, computer, access to network, television, camera, washing machine, air conditioner, water heater, gas stove, refrigerator, kitchen ventilator, and flushable toilet. Each asset was attached with a value and we then calculated the proxy 
variable for value of family wealth by adding the value of all household consumption assets. We did so because recent research has shown household assets to be a more reliable indicator of household wealth than self-reported income. $^{35}$

\section{Randomization and Intervention}

In October 2012, after the baseline survey and vision screening, stratification and random assignment was implemented by researchers. All schools were classified into 42 strata based on the total number of children, the number of children with myopia and the county. There were 6 schools in each stratum which were randomly divided into 6 different groups. They were: control group, education group, free eyeglasses group, education plus free eyeglasses group and 2 different types of interventions. This study only focused on the interventions of education and free eyeglasses. Therefore, this study only included 168 sample schools, one control group (42 schools, 510 myopia students) and three treatment groups: the education group (42 schools, 526 myopia students), free eyeglasses group (42 schools, 527 myopia students), and education plus free eyeglasses group (42 schools, 626 myopia students) (Table 1). All the schools were randomly divided into different treatment groups to ensure that the treatment groups were similar to the control group. Balance tests, which are described below, validate this similarity.

\section{Control Group}

Based on refraction results, children in the control group were only given a prescription, which was noted in a letter to their parents. The students in the control group were not asked to do anything throughout the study. At the end of the intervention and evaluation, the students in this group were given free eyeglasses.

\section{Education Group}

In the education group, myopia students were asked to watch a 10-minute popular science video and obtained a cartoon manual about the popularization of vision knowledge, and our researchers hosted a class discussion. The above materials showed students experiencing and teachers explaining the benefits of eyeglasses. Teachers and parents also watched videos about the safety and benefits of eyeglasses at school, and obtained a science manual of vision knowledge. Posters with the same content were hung in the classroom. All the materials provided to students, teachers, and parents conveyed the same messages: myopia is common in China, it is not terrible to suffer from myopia, wearing eyeglasses is the safest and most effective way to correct myopia, and wearing eyeglasses does not damage the eyesight of students.

\section{Free Eyeglasses Group}

In the free eyeglasses group, each myopia student was provided with a pair of free eyeglasses; at the same time, their parents received a written notice informing them of the student's vision and the corresponding prescription. After students selected frames for their eyeglasses, they received their pair of eyeglasses fitted to the proper prescription at school from a team of an optometrist and two enumerators.

\section{Education Plus Free Eyeglasses Group}

In the education plus free eyeglasses group, all students as well as their teachers and parents in the selected classes participated in the same education campaign as the education group. Each myopia student was provided with a pair of free eyeglasses and their parents received a written notice informing them of the student's vision and the corresponding prescription. Figure 1 shows the experimental design process of this research.

\section{Evaluation Survey}

In May 2013, seven months after the interventions were carried out, an evaluation survey was conducted. The survey procedure consisted of the baseline survey, which also included visual screening and a questionnaire. The study implementation schedule is shown in Figure 2.

\section{Outcome Assessment: Vision Knowledge, Eyeglasses Usage and Eyeglasses Compliance}

This research has two outcome variables: vision knowledge and eyeglasses usage.

Vision knowledge is a variable measured by a student's self-reported survey responses to a series of questions about myopia and eyeglasses usage. The questions are: (1) Knowledge about myopia, (a) Myopia (nearsightedness) causes difficulty in seeing distant objects (yes=1), (b) Myopia is caused by deformed eyeballs (yes=1), (c) Myopia cannot be treated by eye exercise (yes=1), (d) Myopia affects school performance 
Table I Distribution of Sample Schools and Students

\begin{tabular}{|c|c|c|c|c|}
\hline & $\begin{array}{l}\text { Number of } \\
\text { Schools }\end{array}$ & $\begin{array}{c}\text { Number of Students in } \\
\text { Sample Schools }\end{array}$ & $\begin{array}{c}\text { Number of Students Who } \\
\text { Need Glasses }\end{array}$ & $\begin{array}{l}\text { Percentage of } \\
\text { Students }\end{array}$ \\
\hline All sample & 168 & 13,795 & 2,189 & 15.9 \\
\hline \multicolumn{5}{|l|}{ By county } \\
\hline County I & 7 & 500 & 100 & 4.6 \\
\hline County 2 & 7 & 419 & 60 & 2.7 \\
\hline County 3 & 10 & 762 & 145 & 6.6 \\
\hline County 4 & 8 & 610 & 191 & 8.7 \\
\hline County 5 & 8 & 581 & 61 & 2.8 \\
\hline County 6 & 14 & $\mathrm{I}, \mathrm{I} 74$ & 270 & 12.3 \\
\hline County 7 & 9 & 700 & 144 & 6.6 \\
\hline County 8 & 16 & 1,400 & 115 & 5.3 \\
\hline County 9 & 8 & 659 & 67 & 3.1 \\
\hline County 10 & I & 75 & 12 & 0.6 \\
\hline County II & 16 & 1,516 & 224 & 10.2 \\
\hline County 12 & 8 & 720 & 168 & 7.7 \\
\hline County 13 & 16 & $\mathrm{I}, 580$ & 209 & 9.6 \\
\hline County 14 & 8 & 703 & 50 & 2.3 \\
\hline County 15 & 4 & 246 & 39 & 1.8 \\
\hline County 16 & 11 & 785 & 136 & 6.2 \\
\hline County 17 & 9 & 683 & 122 & 5.6 \\
\hline County 18 & 8 & 682 & 76 & 3.5 \\
\hline \multicolumn{5}{|l|}{ By treatment } \\
\hline Control & 42 & 3,587 & 510 & 23.3 \\
\hline Education & 42 & 3,310 & 526 & 24.0 \\
\hline Free eyeglasses, No education & 42 & 3,462 & 527 & 24.1 \\
\hline Free eyeglasses, Education & 42 & 3,436 & 626 & 28.6 \\
\hline \multicolumn{5}{|l|}{ By gender } \\
\hline Female & NA & 6,584 & 1,109 & 50.7 \\
\hline Male & NA & 7,182 & 1,080 & 49.3 \\
\hline \multicolumn{5}{|l|}{ By Province } \\
\hline Gansu & 80 & 7121 & 802 & 11.3 \\
\hline Shaanxi & 88 & 6674 & 1387 & 20.8 \\
\hline
\end{tabular}

Note: Data source, baseline survey.

(yes=1); (2) Knowledge about eyeglasses importance, (a) Wearing proper high-quality eyeglasses at the correct time can correct myopia (yes=1), (b) Eyeglasses are needed even when the degree of myopia is low (yes=1), (c) Wearing eyeglasses does not cause eyesight to get worse (yes=1), (d) Primary school or younger students with myopia should wear eyeglasses (yes=1). Each question is a binary variable (yes or no).

We then constructed two count variables, myopia knowledge and eyeglasses usage knowledge, by adding the number of questions answered correctly (each from 0 to 4$)$. We then constructed the vision knowledge variable (from 0 to 8 ) by adding the myopia knowledge and eyeglasses usage knowledge variables. The higher the score of this variable, the higher the level of visual knowledge of students.

The eyeglasses usage is a binary variable that refers to the information on the wearing of eyeglasses by myopic students, which is measured by whether students were wearing eyeglasses during unannounced visits.

The eyeglasses compliance is a binary variable that refers to the information on whether a student wears eyeglasses regularly in daily life, which is measured by selfreported responses to the question on eyeglasses usage intensity (How often do you wear your eyeglasses? Occasionally use, use at studying, and always use). 


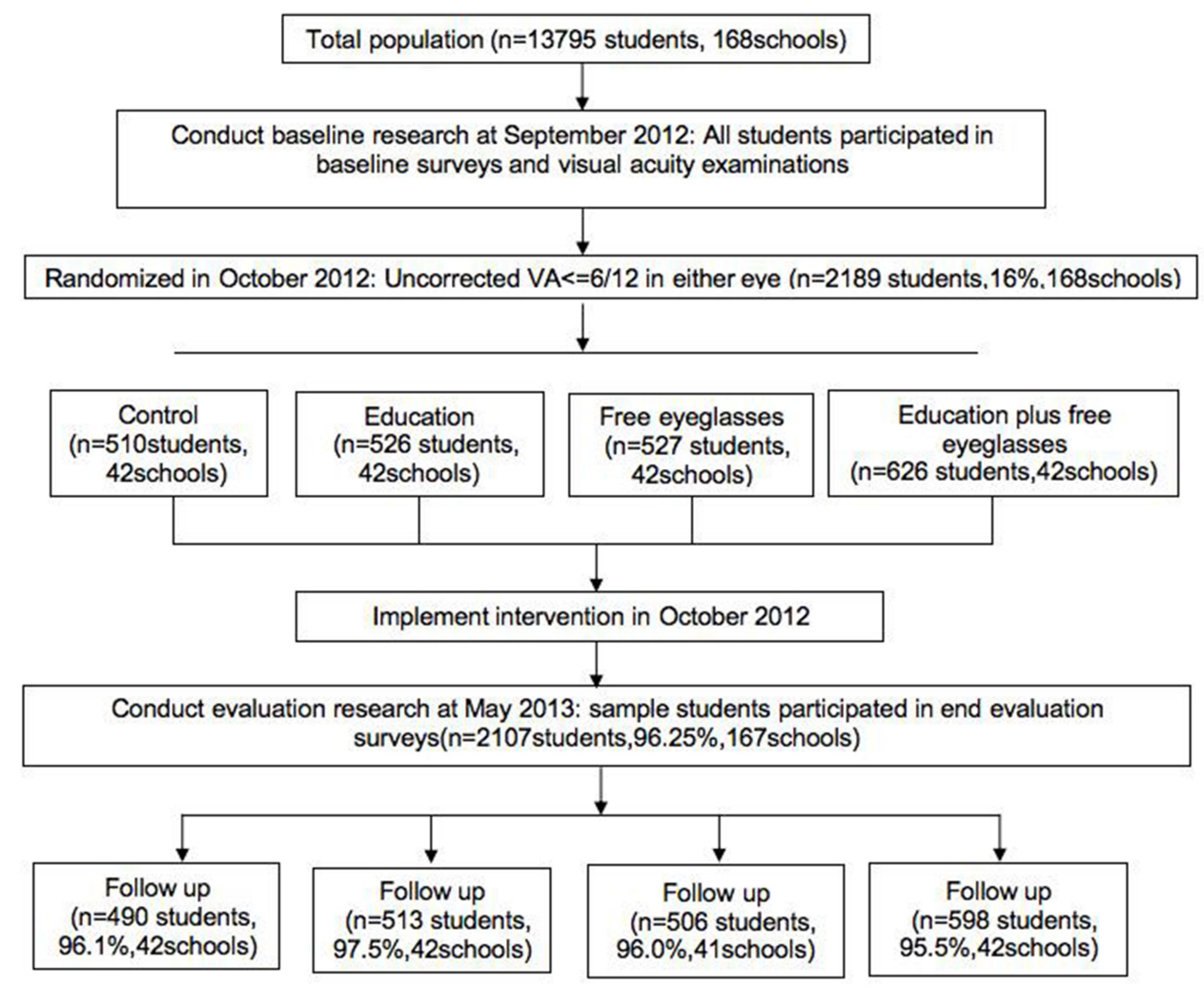

Figure I Schematic diagram describing the sample for the study.

\section{Sample Size}

Using Optimal Design software, we determined that a sample size of 168 schools with a minimum of 15 students for each school conferred $80 \%$ power, with an $\alpha$ of 0.05 , infraclass correlation of 0.15 , and explained variation by covariates (R2) of 0.50 , to detect a difference of 0.20 in evaluation outcome variables between intervention arms and the control group.

\section{Statistical Analysis}

All analyses were performed using Stata 15.1 (StataCorp, College Station, TX), calculating robust standard errors to adjust for clustering by school. The change in vision knowledge, eyeglasses usage and eyeglasses compliance between baseline and evaluation survey was analyzed using Chisquare tests. We compared randomization groups by intention to treat using multiple linear regression, with evaluation survey results vision knowledge, eyeglasses usage and eyeglasses compliance as the main outcome for the main hypothesis and intervention arms and baseline other variables as covariates. Level of significance was set at 5\%.

\section{Results}

Summary Statistics and Balance Checking In total, 13,795 students from 168 rural primary schools were selected (Table 1). Of all students who received vision screening at baseline, there were 2189 (16\%) students whose screening results showed that they need to wear eyeglasses. Only these students are the analysis sample for this study; 526 students, 527 students, and 626 students in the 42 sample schools were randomly assigned to the education group, the free eyeglasses group, and the education plus free eyeglasses group respectively. Their mean age was $10.5( \pm 1.11)$ years $(49.34 \%$ male; $40.06 \%$ fourth grade) . At baseline, the average score for visual knowledge was 2.41 ( \pm 1.61 ), among which the average score of knowledge about myopia was $1.25( \pm 0.96)$ and the average score of knowledge about eyeglasses importance was $1.16( \pm 1.81)$. Only $46 \%$ of sample students were aware of their myopia, and only $15 \%$ who needed eyeglasses used them.

Table 2 shows the balance test result of the sample students' baseline characteristics in each of the intervention groups and the control group. Columns $6-8$ show that the treatment groups were similar in terms of the measured 
Table 2 Summary Statistics and Balance Checking

\begin{tabular}{|c|c|c|c|c|c|c|c|c|c|}
\hline \multirow[t]{4}{*}{ Variables } & (I) & (2) & (3) & (4) & (5) & (6) & (7) & (8) & \multirow{4}{*}{$\begin{array}{c}(9) \\
\begin{array}{c}\text { F-Test } \\
\text { (P-value) }\end{array}\end{array}$} \\
\hline & \multirow{3}{*}{$\begin{array}{c}\text { Full } \\
\text { Sample } \\
(n=2189)\end{array}$} & \multirow{3}{*}{$\begin{array}{l}\text { Control } \\
(n=510)\end{array}$} & \multirow{3}{*}{$\begin{array}{c}\text { Education } \\
(n=526)\end{array}$} & \multirow{3}{*}{$\begin{array}{c}\text { Free } \\
\text { Eyeglasses } \\
(n=527)\end{array}$} & \multirow{3}{*}{$\begin{array}{c}\text { Education Plus } \\
\text { Free Eyeglasses } \\
\quad(n=626)\end{array}$} & \multicolumn{3}{|c|}{$t$-Test (P-value) } & \\
\hline & & & & & & \multicolumn{3}{|c|}{ Difference } & \\
\hline & & & & & & (2)-(3) & (2)-(4) & (2)-(5) & \\
\hline I. Age (Year)-Mean(SD) & $10.51(1.11)$ & $10.53(1.01)$ & $10.56(1.20)$ & $10.47(1.10)$ & $10.47(1.10)$ & 0.690 & 0.332 & 0.331 & 0.426 \\
\hline \multicolumn{10}{|l|}{ 2. Grade-N (\%) } \\
\hline Fourth & $877(40.1)$ & $310(60.8)$ & $307(58.4)$ & $322(6 I .1)$ & $373(59.6)$ & 0.428 & 0.917 & 0.681 & 0.796 \\
\hline Fifth & $1312(49.9)$ & $200(39.2)$ & $219(41.6)$ & $205(38.9)$ & $253(40.4)$ & & & & \\
\hline \multicolumn{10}{|l|}{ 3. Gender-N (\%) } \\
\hline Male & $1080(49.3)$ & $269(52.7)$ & $248(47.2)$ & $253(48.0)$ & $310(49.5)$ & 0.072 & 0.128 & 0.280 & 0.289 \\
\hline Female & $1109(50.7)$ & $24 I(47.3)$ & $278(52.8)$ & $274(52.0)$ & $316(50.5)$ & & & & \\
\hline $\begin{array}{l}\text { 4. Baseline Vison } \\
\text { Knowledge-Mean (SD) }\end{array}$ & $2.4 I(I .6 I)$ & $2.40(1.59)$ & $2.25(1.59)$ & $2.43(1.57)$ & $2.55(1.66)$ & 0.137 & 0.783 & 0.112 & 0.017 \\
\hline $\begin{array}{l}\text { 5. Knowledge about } \\
\text { Myopia-Mean (SD) }\end{array}$ & $1.25(0.96)$ & $1.26(0.97)$ & $1.17(0.96)$ & $1.28(0.94)$ & $1.29(0.96)$ & 0.144 & 0.810 & 0.667 & 0.198 \\
\hline $\begin{array}{l}\text { 6. Knowledge about } \\
\text { Eyeglasses Importance- } \\
\text { Mean (SD) }\end{array}$ & $1.16(1.08)$ & I.14(1.04) & $1.08(1.06)$ & $1.15(1.08)$ & $1.27(1.13)$ & 0.364 & 0.848 & 0.046 & 0.025 \\
\hline \multicolumn{10}{|l|}{ 7. Usage Baseline-N (\%) } \\
\hline Yes & $325(14.9)$ & $85(16.7)$ & $59(\mid 1.2)$ & $81(15.4)$ & $100(16.0)$ & 0.011 & 0.570 & 0.754 & 0.056 \\
\hline No & $1864(85.1)$ & $425(83.3)$ & $467(88.8)$ & $446(84.6)$ & $526(84.0)$ & & & & \\
\hline \multicolumn{10}{|l|}{$\begin{array}{l}\text { 8. Baseline Aware of } \\
\text { Being Myopic-N (\%) }\end{array}$} \\
\hline Yes & $1000(45.7)$ & $237(46.5)$ & $230(43.7)$ & $249(47.3)$ & $284(45.4)$ & 0.357 & 0.872 & 0.712 & 0.706 \\
\hline No & $1189(54.3)$ & $273(53.5)$ & $296(46.3)$ & $278(52.7)$ & $342(54.6)$ & & & & \\
\hline \multicolumn{10}{|l|}{ 9. Living at School-N (\%) } \\
\hline Yes & $52 \mathrm{I}(23.8)$ & $126(24.7)$ & $109(20.7)$ & $129(24.5)$ & $157(25.1)$ & 0.126 & 0.918 & 0.900 & 0.305 \\
\hline No & 1668(76.2) & $384(75.3)$ & $417(79.3)$ & $398(75.5)$ & $469(74.9)$ & & & & \\
\hline $\begin{array}{l}\text { 10. Baseline LogMAR- } \\
\text { Mean (SD) }\end{array}$ & $0.64(0.21)$ & $0.62(0.20)$ & $0.67(0.22)$ & $0.628(0.20)$ & $0.63(0.21)$ & 0.001 & 0.692 & 0.515 & 0.001 \\
\hline $\begin{array}{l}\text { II. Baseline } \\
\text { Standardized Math } \\
\text { Scores-Mean (SD) }\end{array}$ & $0.25(0.99)$ & $0.21(0.20)$ & $0.24(0.98)$ & $0.17(0.99)$ & $0.37(0.95)$ & 0.570 & 0.584 & 0.007 & 0.004 \\
\hline \multicolumn{10}{|l|}{$\begin{array}{l}\text { 12. Father Has High } \\
\text { School Education or } \\
\text { Above-N (\%) }\end{array}$} \\
\hline Yes & $354(16.17)$ & $87(17.06)$ & $76(14.45)$ & $87(16.51)$ & $104(16.61)$ & 0.249 & 0.813 & 0.842 & 0.664 \\
\hline No & $1835(83.83)$ & $423(82.94)$ & $450(85.55)$ & $440(83.49)$ & $522(83.39)$ & & & & \\
\hline \multicolumn{10}{|l|}{$\begin{array}{l}\text { 13. Mother Has High } \\
\text { School Education or } \\
\text { Above-N (\%) }\end{array}$} \\
\hline Yes & $247(\mid 1.28)$ & $45(8.82)$ & $58(11.03)$ & $61(11.57)$ & $83(13.26)$ & 0.237 & 0.144 & 0.018 & 0.133 \\
\hline No & $1942(88.72)$ & $465(91.18)$ & $468(88.97)$ & $466(88.43)$ & $543(86.74)$ & & & & \\
\hline
\end{tabular}

(Continued) 
Table 2 (Continued).

\begin{tabular}{|c|c|c|c|c|c|c|c|c|c|}
\hline \multirow[t]{4}{*}{ Variables } & (I) & (2) & (3) & (4) & (5) & (6) & (7) & (8) & (9) \\
\hline & \multirow{3}{*}{$\begin{array}{c}\text { Full } \\
\text { Sample } \\
(n=2189)\end{array}$} & \multirow{3}{*}{$\begin{array}{l}\text { Control } \\
(n=5 \mid 0)\end{array}$} & \multirow{3}{*}{$\begin{array}{c}\text { Education } \\
(n=526)\end{array}$} & \multirow{3}{*}{$\begin{array}{c}\text { Free } \\
\text { Eyeglasses } \\
(n=527)\end{array}$} & \multirow{3}{*}{$\begin{array}{l}\text { Education Plus } \\
\text { Free Eyeglasses } \\
\qquad(n=626)\end{array}$} & \multicolumn{3}{|c|}{$t$-Test (P-value) } & \multirow{3}{*}{$\begin{array}{c}\text { F-Test } \\
\text { (P-value) }\end{array}$} \\
\hline & & & & & & \multicolumn{3}{|c|}{ Difference } & \\
\hline & & & & & & (2)-(3) & (2)-(4) & (2)-(5) & \\
\hline \multirow{2}{*}{\multicolumn{10}{|c|}{$\begin{array}{l}\text { 14. Both Parents } \\
\text { Migrated for Work-N (\%) }\end{array}$}} \\
\hline & & & & & & & & & \\
\hline Yes & $221(10.10)$ & $39(7.65)$ & $65(12.36)$ & $54(10.25)$ & $63(10.06)$ & 0.011 & 0.144 & 0.157 & 0.096 \\
\hline No & $1968(89.90)$ & $47 \mid(92.35)$ & $461(87.64)$ & $473(89.75)$ & $563(89.94)$ & 0.120 & 0.462 & 0.814 & 0.141 \\
\hline $\begin{array}{l}\text { 15. Household Wealth- } \\
\text { Mean (SD) }\end{array}$ & $2.18(0.79)$ & $2.19(0.78)$ & $2.12(0.77)$ & $2.23(0.80)$ & $2.18(0.79)$ & & & & \\
\hline \multicolumn{10}{|l|}{ 16. Province-N (\%) } \\
\hline Gansu & $802(36.64)$ & $187(36.67)$ & $210(39.92)$ & $17 \mid(32.45)$ & $234(37.38)$ & 0.282 & 0.153 & 0.804 & 0.087 \\
\hline Shaanxi & $1387(63.36)$ & $323(63.33)$ & $316(60.08)$ & $356(67.55)$ & $392(62.62)$ & & & & \\
\hline
\end{tabular}

Notes: Data source, baseline survey; this table shows the demographic characteristics of different intervention groups and their differences; the characteristics in the full sample, control group, education group, free eyeglasses group, and education plus free eyeglasses group respectively for columns (I)-(5); The difference between sample students in the treatment groups and control group for columns (6)-(8); column (9) suggests the p-value of the joint hypothesis test.

characteristics to the control group. Column 9 shows that the joint significance test across all baseline characteristics confirms that the study arms are balanced.

Figure 1 indicates the long-term attrition of research samples was limited (Figure 1). Among the 2,189 sample students, only $76(3.5 \%)$ could not be tracked in long-term follow-up. Table 3 indicates that there are no statistically significant differences in the rates of attrition between the treatment groups and control group.

Vision Knowledge, Eyeglasses Usage, and Eyeglasses Compliance in Baseline to the Evaluation Time

Table 4 (Panel A) illustrates the students' vision knowledge. At the baseline, the average correct response rate of knowledge about myopia is $31.3 \%(1.25 / 4)$ in all sample students. In the evaluation stage, the average correct response rate increased, ranging from $37.5 \%(1.50 / 4)$ to $44.5 \%(1.78 / 4)$ in the treatment groups.

Similarly, at the baseline, the average correct response rate of knowledge about eyeglasses importance is $29.0 \%$ $(1.16 / 4)$ in all sample students. In the evaluation stage, the average correct response rate increased, ranging from $37.0 \%(1.48 / 4)$ to $53.5 \%(2.14 / 4)$ in the treatment groups.

And, at the baseline, the average correct response rate of vision knowledge is $30.1 \%$ (2.41/8) in all sample students. In the evaluation stage, the average correct response rate increased, ranging from $37.3 \%(2.98 / 8)$ to $48.8 \%(3.91 / 8)$ in the treatment groups.

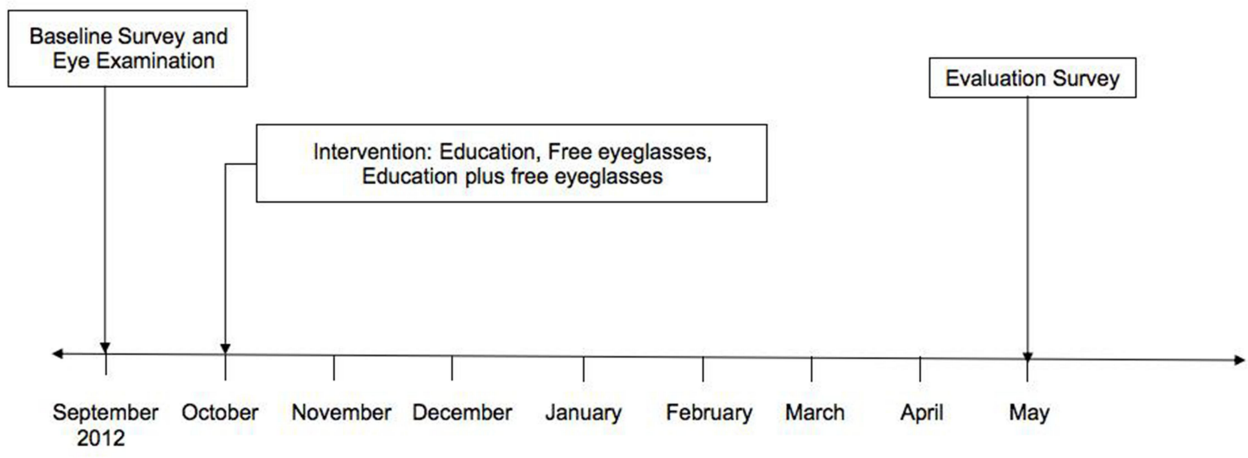

Figure 2 The data collection and intervention timeline. 
The answers for each vision knowledge item are shown in Table 5, which is similar to the results of Table 4. Both results showed that compared with the control group, vision health education alone or education plus free eyeglasses can significantly improve students' visual knowledge. Distribution of free eyeglasses alone cannot improve vision knowledge.

Table 4 (Panel B) shows the eyeglasses usage and compliance of students. At the baseline, the rate of eyeglasses usage is $14.9 \%$ in all sample students. In the evaluation stage, the rate increased, ranging from $26.3 \%$ to $44.0 \%$ in the treatment groups. Three different interventions significantly increased the eyeglasses usage.

At the evaluation stage, the rate of eyeglasses compliance is $15.4 \%$ in the control group, and ranges from $18.5 \%$ to $27.8 \%$ in the treatment groups. Providing free eyeglasses or education plus free eyeglasses delivery both have positive impacts. Providing vision health education only did not affect students' eyeglasses compliance.

\section{Average Impacts of Different Interventions on Student Vision Knowledge, Eyeglasses Usage and Eyeglasses Compliance}

Multivariate analysis (Table 6) indicates the average score of vision knowledge among students in the control group was about 2.93. The average score of vision knowledge in the education group was 3.88 , which was 0.95 points higher than that in the control group. The average score in the education plus free eyeglasses group was 3.86, which was 0.93 points higher than that in the control group. These results are significant at the $1 \%$ level. After controlling for the characteristics of students and their families, the multivariate model result shows a similar story: the vision health education and education plus free eyeglasses both had positive impacts on students' vision knowledge. Providing free eyeglasses only did not affect students' vision knowledge.

The result of eyeglasses usage and compliance indicates that eyeglasses usage and compliance in the free eyeglasses group and education plus free eyeglasses group was significantly higher than that in the control group. Education combined with free eyeglasses had a stronger impact on student eyeglasses usage and compliance. Providing education only cannot influence eyeglasses usage. Results from the multivariate regression model show that the average eyeglasses usage rate among students in the control group was $\sim 25 \%$. Eyeglasses usage increased by 11 percentage points tto $36 \%$ among students in the free eyeglasses group and increased by 18 percentage points to $43 \%$ in the education plus free eyeglasses group. The eyeglasses compliance rate was $15 \%$ in the control group, $19 \%$ in the education group (higher by 4 percentage points than the control group), and $26 \%$ in the education plus free glasses group (higher by 11 percentage points than the control group). These results are also significant at the $5 \%$ level.

\section{Conclusions and Discussion}

The study examines the effect of an information campaign and free trial both on the knowledge and usage of health products in rural China, using data from a field randomized controlled experiment of a program providing vision health information and subsidized eyeglasses for myopic students. Firstly, we describe the vision knowledge and eyeglasses usage of primary school students in the sample rural areas. We then estimated the average impact of providing vision health education and subsidizing free eyeglasses on students' vision knowledge, eyeglasses usage and eyeglasses compliance.

This study revealed that at the baseline, vision health knowledge of the students in the sample area was seriously insufficient. The baseline average correct response rate of vision knowledge range between $28.1 \%$ and $31.9 \%$. This is consistent with other research, indicating serious misinformation of vision knowledge in rural areas. ${ }^{12,16-18,36}$ After carrying out interventions, the students' vision knowledge was improved. The average correct response rate of vision knowledge increased, ranging from $37.3 \%$ to $48.8 \%$ in the treatment groups. Compared with the control group, the increase of students' vision knowledge in the education group and the education plus free eyeglasses group was significant.

The eyeglasses usage rate in students with myopia at the baseline is low, it ranged from $11.3 \%$ to $16.1 \%$, which is similar to other studies in rural China. ${ }^{11}$ After interventions, the eyeglasses usage rate of students increased, ranging from $26.3 \%$ to $44.0 \%$ in the treatment groups. Compared with the control group, the increase of eyeglasses usage in the free eyeglasses group and the education plus free eyeglasses group was significant.

The results from our randomized controlled experiment show that education improves students' vision health knowledge significantly compared with subsidized eyeglasses alone, but not the eyeglasses usage rate, and 
Table 3 Balance Check of Baseline Characteristics of the Remaining Sample Across Experimental Group

\begin{tabular}{|c|c|c|c|c|c|c|c|c|}
\hline Variables & $(1)$ & $(2)$ & $(3)$ & $(4)$ & $(5)$ & $(6)$ & $(7)$ & $(8)$ \\
\cline { 2 - 7 } & $\begin{array}{c}\text { Age } \\
\text { (Year) }\end{array}$ & $\begin{array}{c}\text { Grade 5 } \\
(I-Y e s)\end{array}$ & $\begin{array}{c}\text { Male } \\
(I=Y e s)\end{array}$ & $\begin{array}{c}\text { Baseline } \\
\text { Vison } \\
\text { Knowledge } \\
(0-8)\end{array}$ & $\begin{array}{c}\text { Myopia } \\
\text { Knowledge } \\
(0-4)\end{array}$ & $\begin{array}{c}\text { Eyeglasses } \\
\text { Usage } \\
\text { Knowledge } \\
(0-4)\end{array}$ & $\begin{array}{c}\text { Owns } \\
\text { Eyeglasses } \\
(I=Y e s)\end{array}$ & $\begin{array}{c}\text { Baseline } \\
\text { Aware of } \\
\text { Being Myopic } \\
(I=Y e s)\end{array}$ \\
\end{tabular}

Panel A: Balance between Control and Education group accounting for attrition in follow-up

\begin{tabular}{|c|c|c|c|c|c|c|c|c|}
\hline Education & $\begin{array}{c}0.018 \\
(0.115)\end{array}$ & $\begin{array}{l}-0.031 \\
(0.033)\end{array}$ & $\begin{array}{l}-0.053 \\
(0.032)\end{array}$ & $\begin{array}{l}-0.146 \\
(0.131)\end{array}$ & $\begin{array}{l}-0.088 \\
(0.075)\end{array}$ & $\begin{array}{l}-0.059 \\
(0.094)\end{array}$ & $\begin{array}{l}-0.048 * \\
(0.028)\end{array}$ & $\begin{array}{l}-0.019 \\
(0.047)\end{array}$ \\
\hline $\begin{array}{l}\text { Attrition between } \\
\text { baseline and evaluation }\end{array}$ & $\begin{array}{l}-0.170 \\
(0.266)\end{array}$ & $\begin{array}{l}-0.164 * \\
(0.097)\end{array}$ & $\begin{array}{l}-0.081 \\
(0.121)\end{array}$ & $\begin{array}{c}0.158 \\
(0.467)\end{array}$ & $\begin{array}{c}0.143 \\
(0.276)\end{array}$ & $\begin{array}{c}0.015 \\
(0.265)\end{array}$ & $\begin{array}{c}0.139 \\
(0.087)\end{array}$ & $\begin{array}{l}0.115 \\
(0.115)\end{array}$ \\
\hline Interaction_attr I & $\begin{array}{c}0.306 \\
(0.577)\end{array}$ & $\begin{array}{l}0.197 \\
(0.189)\end{array}$ & $\begin{array}{l}-0.166 \\
(0.175)\end{array}$ & $\begin{array}{c}0.058 \\
(0.638)\end{array}$ & $\begin{array}{c}0.072 \\
(0.390)\end{array}$ & $\begin{array}{l}-0.014 \\
(0.366)\end{array}$ & $\begin{array}{l}-0.175 \\
(0.115)\end{array}$ & $\begin{array}{r}-0.329 * * \\
(0.151)\end{array}$ \\
\hline Constant & $\begin{array}{l}10.539 * * * \\
(0.064)\end{array}$ & $\begin{array}{c}0.614^{* * * *} \\
(0.022)\end{array}$ & $\begin{array}{l}0.53 I^{* * * *} \\
(0.02 I)\end{array}$ & $\begin{array}{c}2.392 * * * \\
(0.079)\end{array}$ & $\begin{array}{l}\text { I.257*** } \\
(0.057)\end{array}$ & $\begin{array}{l}1.135 * * * \\
(0.046)\end{array}$ & $\begin{array}{l}0.16 I^{* * * *} \\
(0.022)\end{array}$ & $\begin{array}{r}0.464 * * * \\
(0.029)\end{array}$ \\
\hline R-squared & 0.001 & 0.003 & 0.007 & 0.003 & 0.003 & 0.001 & 0.009 & 0.004 \\
\hline Block Fixed Effects & YES & YES & YES & YES & YES & YES & YES & YES \\
\hline
\end{tabular}

Panel B: Balance between Control and Free-glasses (no education) group accounting for attrition in follow-up

\begin{tabular}{|c|c|c|c|c|c|c|c|c|}
\hline Free eyeglasses & $\begin{array}{l}-0.074 \\
(0.100)\end{array}$ & $\begin{array}{l}-0.008 \\
(0.033)\end{array}$ & $\begin{array}{l}-0.050 \\
(0.034)\end{array}$ & $\begin{array}{l}0.045 \\
(0.124)\end{array}$ & $\begin{array}{c}0.027 \\
(0.092)\end{array}$ & $\begin{array}{l}0.017 \\
(0.077)\end{array}$ & $\begin{array}{l}-0.005 \\
(0.031)\end{array}$ & $\begin{array}{l}0.015 \\
(0.04 I)\end{array}$ \\
\hline $\begin{array}{l}\text { Attrition between } \\
\text { baseline and evaluation }\end{array}$ & $\begin{array}{l}-0.170 \\
(0.266)\end{array}$ & $\begin{array}{l}-0.164 * \\
(0.097)\end{array}$ & $\begin{array}{l}-0.081 \\
(0.121)\end{array}$ & $\begin{array}{l}0.158 \\
(0.467)\end{array}$ & $\begin{array}{c}0.143 \\
(0.276)\end{array}$ & $\begin{array}{c}0.015 \\
(0.265)\end{array}$ & $\begin{array}{c}0.139 \\
(0.087)\end{array}$ & $\begin{array}{l}0.115 \\
(0.115)\end{array}$ \\
\hline Interaction_attr2 & $\begin{array}{c}0.277 \\
(0.428)\end{array}$ & $\begin{array}{l}0.272^{*} \\
(0.158)\end{array}$ & $\begin{array}{c}0.077 \\
(0.173)\end{array}$ & $\begin{array}{l}-0.452 \\
(0.547)\end{array}$ & $\begin{array}{l}-0.332 \\
(0.348)\end{array}$ & $\begin{array}{l}-0.120 \\
(0.378)\end{array}$ & $\begin{array}{l}-0.200 * \\
(0.106)\end{array}$ & $\begin{array}{l}-0.261 \\
(0.182)\end{array}$ \\
\hline Constant & $\begin{array}{c}10.539 * * * \\
(0.064)\end{array}$ & $\begin{array}{c}0.614^{* * * *} \\
(0.022)\end{array}$ & $\begin{array}{l}0.531 * * * \\
(0.021)\end{array}$ & $\begin{array}{c}2.392 * * * \\
(0.079)\end{array}$ & $\begin{array}{l}1.257^{* * *} \\
(0.057)\end{array}$ & $\begin{array}{l}\text { I.I } 135 * * * \\
(0.046)\end{array}$ & $\begin{array}{l}0.161 * * * \\
(0.022)\end{array}$ & $\begin{array}{r}0.464^{* * * *} \\
(0.029)\end{array}$ \\
\hline R-squared & 0.002 & 0.003 & 0.003 & 0.001 & 0.001 & 0.000 & 0.004 & 0.003 \\
\hline Block Fixed Effects & YES & YES & YES & YES & YES & YES & YES & YES \\
\hline
\end{tabular}

Panel C: Balance between Control and Free-glasses (and education) group accounting for attrition in follow-up

\begin{tabular}{|c|c|c|c|c|c|c|c|c|}
\hline $\begin{array}{l}\text { Education plus free } \\
\text { eyeglasses }\end{array}$ & $\begin{array}{l}-0.103 \\
(0.119)\end{array}$ & $\begin{array}{l}-0.024 \\
(0.032)\end{array}$ & $\begin{array}{l}-0.032 \\
(0.030)\end{array}$ & $\begin{array}{l}0.155 \\
(0.122)\end{array}$ & $\begin{array}{c}0.039 \\
(0.070)\end{array}$ & $\begin{array}{c}0.116 \\
(0.079)\end{array}$ & $\begin{array}{l}-0.001 \\
(0.030)\end{array}$ & $\begin{array}{l}-0.010 \\
(0.043)\end{array}$ \\
\hline $\begin{array}{l}\text { Attrition between } \\
\text { baseline and evaluation }\end{array}$ & $\begin{array}{l}-0.170 \\
(0.265)\end{array}$ & $\begin{array}{l}-0.164 * \\
(0.097)\end{array}$ & $\begin{array}{l}-0.081 \\
(0.121)\end{array}$ & $\begin{array}{l}0.158 \\
(0.467)\end{array}$ & $\begin{array}{c}0.143 \\
(0.276)\end{array}$ & $\begin{array}{c}0.015 \\
(0.265)\end{array}$ & $\begin{array}{c}0.139 \\
(0.087)\end{array}$ & $\begin{array}{l}0.115 \\
(0.115)\end{array}$ \\
\hline Interaction_attr3 & $\begin{array}{l}0.949 * * \\
(0.370)\end{array}$ & $\begin{array}{l}0.288 * * \\
(0.131)\end{array}$ & $\begin{array}{c}0.011 \\
(0.151)\end{array}$ & $\begin{array}{l}-0.026 \\
(0.591)\end{array}$ & $\begin{array}{l}-0.332 \\
(0.327)\end{array}$ & $\begin{array}{c}0.305 \\
(0.374)\end{array}$ & $\begin{array}{l}-0.156 \\
(0.108)\end{array}$ & $\begin{array}{l}-0.033 \\
(0.140)\end{array}$ \\
\hline Constant & $\begin{array}{l}10.539 * * * \\
(0.064)\end{array}$ & $\begin{array}{c}0.614 * * * \\
(0.022)\end{array}$ & $\begin{array}{c}0.531 * * * \\
(0.021)\end{array}$ & $\begin{array}{c}2.392 * * * \\
(0.079)\end{array}$ & $\begin{array}{l}\text { I.257*** } \\
(0.057)\end{array}$ & $\begin{array}{l}\text { I.I35*** } \\
(0.046)\end{array}$ & $\begin{array}{c}0.161^{* * *} \\
(0.022)\end{array}$ & $\begin{array}{r}0.464^{* * * *} \\
(0.029)\end{array}$ \\
\hline R-squared & 0.014 & 0.004 & 0.002 & 0.003 & 0.001 & 0.006 & 0.003 & 0.002 \\
\hline Block Fixed Effects & YES & YES & YES & YES & YES & YES & YES & YES \\
\hline
\end{tabular}

Notes: Data source, baseline survey and evaluation survey; Study tested whether the effects of different treatments on vision knowledge and eyeglasses usage are biased due to sample attrition. For this, we first constructed a variable representing attrition $(I=$ attrition). Then, study used treatment variable, attrition variable, and interaction variable between the two to regress different baseline covariates and adjusted for school level cluster; robust standard errors in parentheses; ${ }^{* * *}$ significant at the $1 \%$ level; **significant at the $5 \%$ level; *significant at the $10 \%$ level. 


\begin{tabular}{|c|c|c|c|c|c|c|c|}
\hline (9) & (10) & (II) & (12) & (13) & (14) & (15) & (16) \\
\hline $\begin{array}{l}\text { Living } \\
\text { at } \\
\text { School } \\
\text { (I=Yes) }\end{array}$ & $\begin{array}{l}\text { Baseline Visual } \\
\text { Acuity of Worse } \\
\text { Eye (LogMAR) }\end{array}$ & $\begin{array}{c}\text { Baseline } \\
\text { Standardized } \\
\text { Math Scores }\end{array}$ & $\begin{array}{c}\text { Father Has High } \\
\text { School Education } \\
\text { or Above } \\
\text { (I=Yes) }\end{array}$ & $\begin{array}{c}\text { Mother Has High } \\
\text { School Education } \\
\text { or Above } \\
(I=\text { Yes })\end{array}$ & $\begin{array}{l}\text { Both } \\
\text { Parents } \\
\text { Migrated } \\
\text { for Work } \\
\text { (I=Yes) }\end{array}$ & $\begin{array}{l}\text { Household } \\
\text { Wealth } \\
\text { (Index) }\end{array}$ & $\begin{array}{l}\text { Province } \\
\text { (I=Gansu) }\end{array}$ \\
\hline $\begin{array}{l}-0.036 \\
(0.07 I)\end{array}$ & $\begin{array}{l}0.050 \text { ** } \\
(0.022)\end{array}$ & $\begin{array}{c}0.057 \\
(0.102)\end{array}$ & $\begin{array}{l}-0.025 \\
(0.027)\end{array}$ & $\begin{array}{c}0.025 \\
(0.025)\end{array}$ & $\begin{array}{l}0.044^{*} \\
(0.022)\end{array}$ & $\begin{array}{l}-0.069 \\
(0.093)\end{array}$ & $\begin{array}{c}0.026 \\
(0.119)\end{array}$ \\
\hline $\begin{array}{l}0.21 I^{* *} \\
(0.083)\end{array}$ & $\begin{array}{c}0.023 \\
(0.064)\end{array}$ & $\begin{array}{c}0.062 \\
(0.224)\end{array}$ & $\begin{array}{c}0.083 \\
(0.094)\end{array}$ & $\begin{array}{c}0.116 \\
(0.096)\end{array}$ & $\begin{array}{l}0.18 I^{* *} \\
(0.087)\end{array}$ & $\begin{array}{c}0.058 \\
(0.212)\end{array}$ & $\begin{array}{c}-0.278 * * * \\
(0.080)\end{array}$ \\
\hline $\begin{array}{l}-0.029 \\
(0.149)\end{array}$ & $\begin{array}{l}-0.057 \\
(0.080)\end{array}$ & $\begin{array}{c}-0.87 I^{* *} \\
(0.425)\end{array}$ & $\begin{array}{c}0.006 \\
(0.147)\end{array}$ & $\begin{array}{l}-0.072 \\
(0.135)\end{array}$ & $\begin{array}{c}0.245 \\
(0.167)\end{array}$ & $\begin{array}{l}-0.431 \\
(0.333)\end{array}$ & $\begin{array}{c}0.105 \\
(0.143)\end{array}$ \\
\hline $\begin{array}{c}0.239 * * * \\
(0.054)\end{array}$ & $\begin{array}{c}0.622^{* * *} \\
(0.013)\end{array}$ & $\begin{array}{l}0.204 * * \\
(0.08 I)\end{array}$ & $\begin{array}{c}0.167^{* * *} \\
(0.019)\end{array}$ & $\begin{array}{c}0.084 * * * \\
(0.017)\end{array}$ & $\begin{array}{c}0.069 * * * \\
(0.014)\end{array}$ & $\begin{array}{c}2.192 * * * \\
(0.065)\end{array}$ & $\begin{array}{c}0.378 * * * \\
(0.083)\end{array}$ \\
\hline 0.009 & 0.013 & 0.008 & 0.003 & 0.004 & 0.037 & 0.004 & 0.009 \\
\hline YES & YES & YES & YES & YES & YES & YES & YES \\
\hline $\begin{array}{l}-0.002 \\
(0.075)\end{array}$ & $\begin{array}{c}0.007 \\
(0.018)\end{array}$ & $\begin{array}{l}-0.031 \\
-0.106\end{array}$ & $\begin{array}{l}-0.003 \\
(0.027)\end{array}$ & $\begin{array}{c}0.031 \\
(0.026)\end{array}$ & $\begin{array}{c}0.027 \\
(0.021)\end{array}$ & $\begin{array}{c}0.043 \\
(0.096)\end{array}$ & $\begin{array}{l}-0.046 \\
(0.116)\end{array}$ \\
\hline $\begin{array}{l}0.211^{* *} \\
(0.083)\end{array}$ & $\begin{array}{c}0.023 \\
(0.064)\end{array}$ & $\begin{array}{c}0.062 \\
-0.224\end{array}$ & $\begin{array}{c}0.083 \\
(0.094)\end{array}$ & $\begin{array}{c}0.116 \\
(0.096)\end{array}$ & $\begin{array}{l}0.18 I^{* * *} \\
(0.087)\end{array}$ & $\begin{array}{c}0.058 \\
(0.211)\end{array}$ & $\begin{array}{c}-0.278^{* * *} \\
(0.080)\end{array}$ \\
\hline $\begin{array}{l}-0.019 \\
(0.159)\end{array}$ & $\begin{array}{l}-0.057 \\
(0.077)\end{array}$ & $\begin{array}{l}-0.101 \\
-0.353\end{array}$ & $\begin{array}{l}-0.056 \\
(0.123)\end{array}$ & $\begin{array}{l}-0.088 \\
(0.127)\end{array}$ & $\begin{array}{l}-0.039 \\
(0.128)\end{array}$ & $\begin{array}{l}-0.150 \\
(0.287)\end{array}$ & $\begin{array}{c}0.088 \\
(0.122)\end{array}$ \\
\hline $\begin{array}{c}0.239 * * * \\
(0.054)\end{array}$ & $\begin{array}{c}0.622^{* * *} \\
(0.013)\end{array}$ & $\begin{array}{l}0.204 * * \\
-0.08 I\end{array}$ & $\begin{array}{c}0.167^{* * *} \\
(0.019)\end{array}$ & $\begin{array}{c}0.084 * * * \\
(0.017)\end{array}$ & $\begin{array}{c}0.069 * * * \\
(0.014)\end{array}$ & $\begin{array}{c}2.192 * * * \\
(0.065)\end{array}$ & $\begin{array}{c}0.378 * * * \\
(0.083)\end{array}$ \\
\hline 0.008 & 0.001 & 0 & 0.001 & 0.005 & 0.014 & 0.001 & 0.011 \\
\hline YES & YES & YES & YES & YES & YES & YES & YES \\
\hline $\begin{array}{c}0.010 \\
(0.076)\end{array}$ & $\begin{array}{c}0.007 \\
(0.017)\end{array}$ & $\begin{array}{l}0.176^{*} \\
-0.101\end{array}$ & $\begin{array}{l}-0.002 \\
(0.025)\end{array}$ & $\begin{array}{l}0.045^{*} \\
(0.025)\end{array}$ & $\begin{array}{c}0.029 \\
(0.020)\end{array}$ & $\begin{array}{c}0.004 \\
(0.106)\end{array}$ & $\begin{array}{l}-0.013 \\
(0.118)\end{array}$ \\
\hline $\begin{array}{l}0.211 * * \\
(0.083)\end{array}$ & $\begin{array}{c}0.023 \\
(0.064)\end{array}$ & $\begin{array}{c}0.062 \\
-0.224\end{array}$ & $\begin{array}{c}0.083 \\
(0.094)\end{array}$ & $\begin{array}{c}0.116 \\
(0.096)\end{array}$ & $\begin{array}{l}0.181^{* *} \\
(0.087)\end{array}$ & $\begin{array}{c}0.058 \\
(0.211)\end{array}$ & $\begin{array}{c}-0.278 * * * \\
(0.080)\end{array}$ \\
\hline $\begin{array}{l}-0.174 \\
(0.122)\end{array}$ & $\begin{array}{c}0.027 \\
(0.08 I)\end{array}$ & $\begin{array}{l}-0.329 \\
-0.292\end{array}$ & $\begin{array}{l}-0.070 \\
(0.119)\end{array}$ & $\begin{array}{l}-0.031 \\
(0.123)\end{array}$ & $\begin{array}{l}-0.136 \\
(0.112)\end{array}$ & $\begin{array}{l}-0.365 \\
(0.256)\end{array}$ & $\begin{array}{c}0.484 * * * \\
(0.120)\end{array}$ \\
\hline $\begin{array}{c}0.239 * * * \\
(0.054)\end{array}$ & $\begin{array}{c}0.622^{* * *} \\
(0.013)\end{array}$ & $\begin{array}{l}0.204 * * \\
-0.081\end{array}$ & $\begin{array}{c}0.167^{* * *} \\
(0.019)\end{array}$ & $\begin{array}{c}0.084 * * * \\
(0.017)\end{array}$ & $\begin{array}{c}0.069 * * * \\
(0.014)\end{array}$ & $\begin{array}{c}2.192^{* * * *} \\
(0.065)\end{array}$ & $\begin{array}{c}0.378 * * * \\
(0.083)\end{array}$ \\
\hline 0.004 & 0.002 & 0.008 & 0.001 & 0.009 & 0.009 & 0.004 & 0.010 \\
\hline YES & YES & YES & YES & YES & YES & YES & YES \\
\hline
\end{tabular}




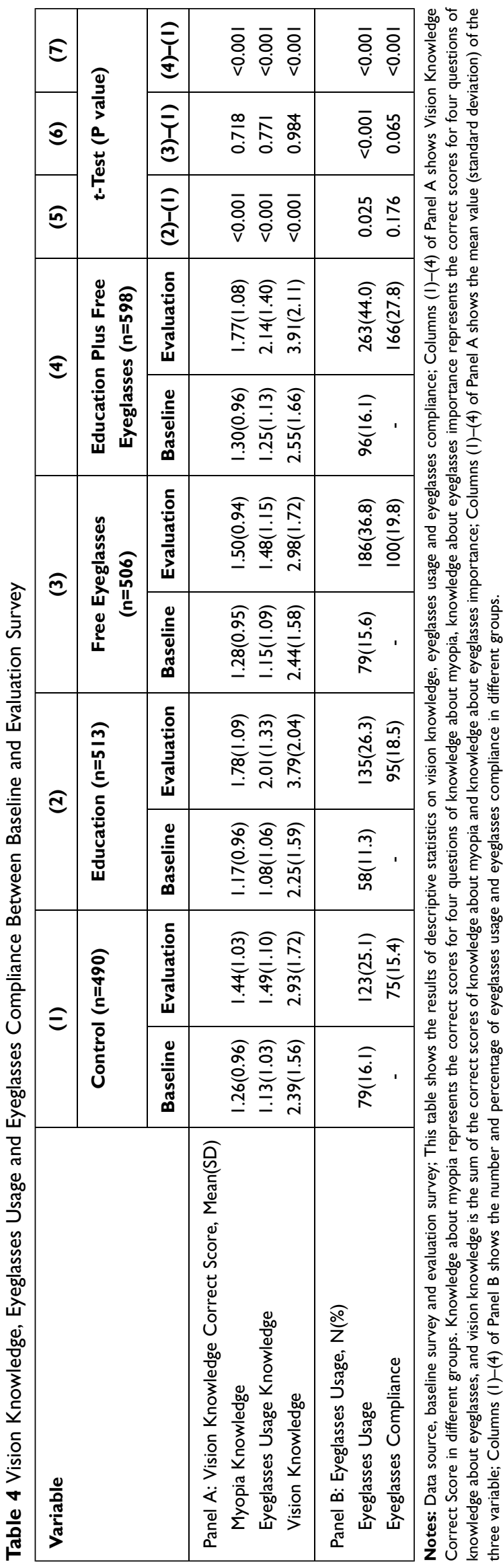

subsidized eyeglasses dramatically increase the uptake of and compliance with eyeglasses compared with education alone, but not the level of vision health knowledge. Vision health education combined with subsidized eyeglasses improves both the students' vision health knowledge and eyeglasses usage rate, even eyeglasses compliance.

These findings may imply the different impact and mechanisms of information and subsidies on increasing the rate of healthcare uptake. Economists generally believe that a low adoption rate means the expected costs of buying the product and the effort to use it are greater than the expected benefits. ${ }^{37}$ To increase take up and usage rate, one needs to either lower the cost (and the expected cost) or increase the benefits (and the expected benefits).

In our case, the information campaign changes the vision knowledge significantly, it increases the perceived benefits of wearing eyeglasses by providing the right information and knowledge directly. Cases where there is no impact on healthcare uptake may be due to financial constraints. Subsidized eyeglasses are effective for lowering the costs of purchase, which dramatically increases the uptake of healthcare in the short term. Although a study by Shi et al. (2020) has shown that a free trial is an effective strategy to solve the problem of information asymmetry in health care, ${ }^{27}$ it takes time to deliver health benefits and change the perceived cost and benefits. When information is paired with subsidized health care (a pair of free eyeglasses), interventions may change the cost and the benefits of a theoretical assumption. This finding highlights the work of others that have shown the complementary relationship between information and subsidies in expanding health care. ${ }^{30,38}$

Studies have confirmed that only recognizing possible health risks and related knowledge is usually not enough to persuade vulnerable groups to seek out care. ${ }^{23,39}$ Considering that our sample families are from a particularly poor province, the cost of a pair of eyeglasses may be an even greater share of a family's monthly income. Therefore, providing information alone is not sufficient when such costs are involved.

Likewise, only offering free healthcare products may have limited effect on fostering habits of using healthy products. ${ }^{39}$ Studies have shown that many misconceptions such as eyeglasses worsening vision ${ }^{16,18}$ lead to low rates of compliance. Especially in our experimental sample area, misinformation and insufficient understanding of the benefit of wearing eyeglasses are very common. ${ }^{3,12}$ This means that 


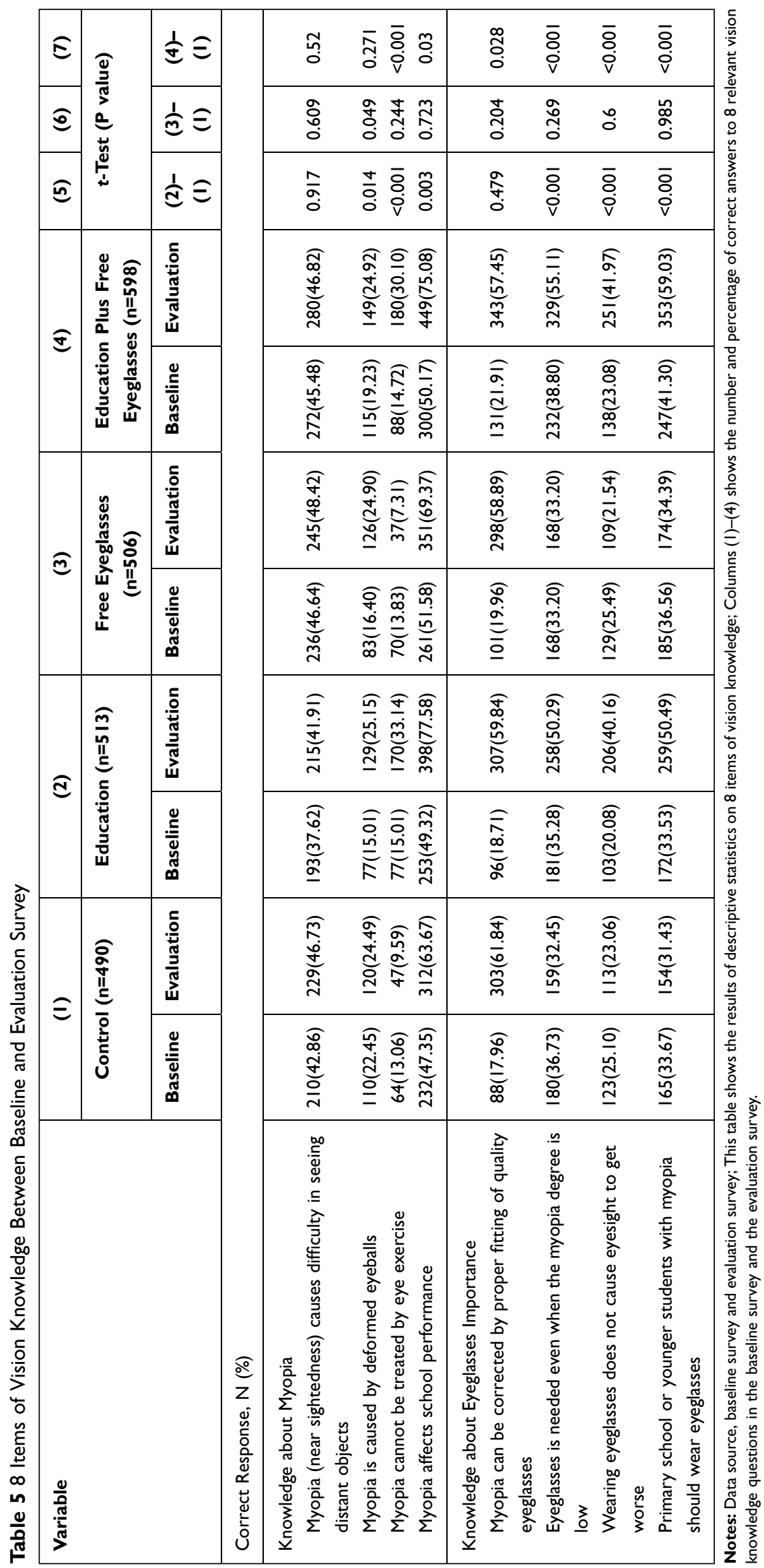




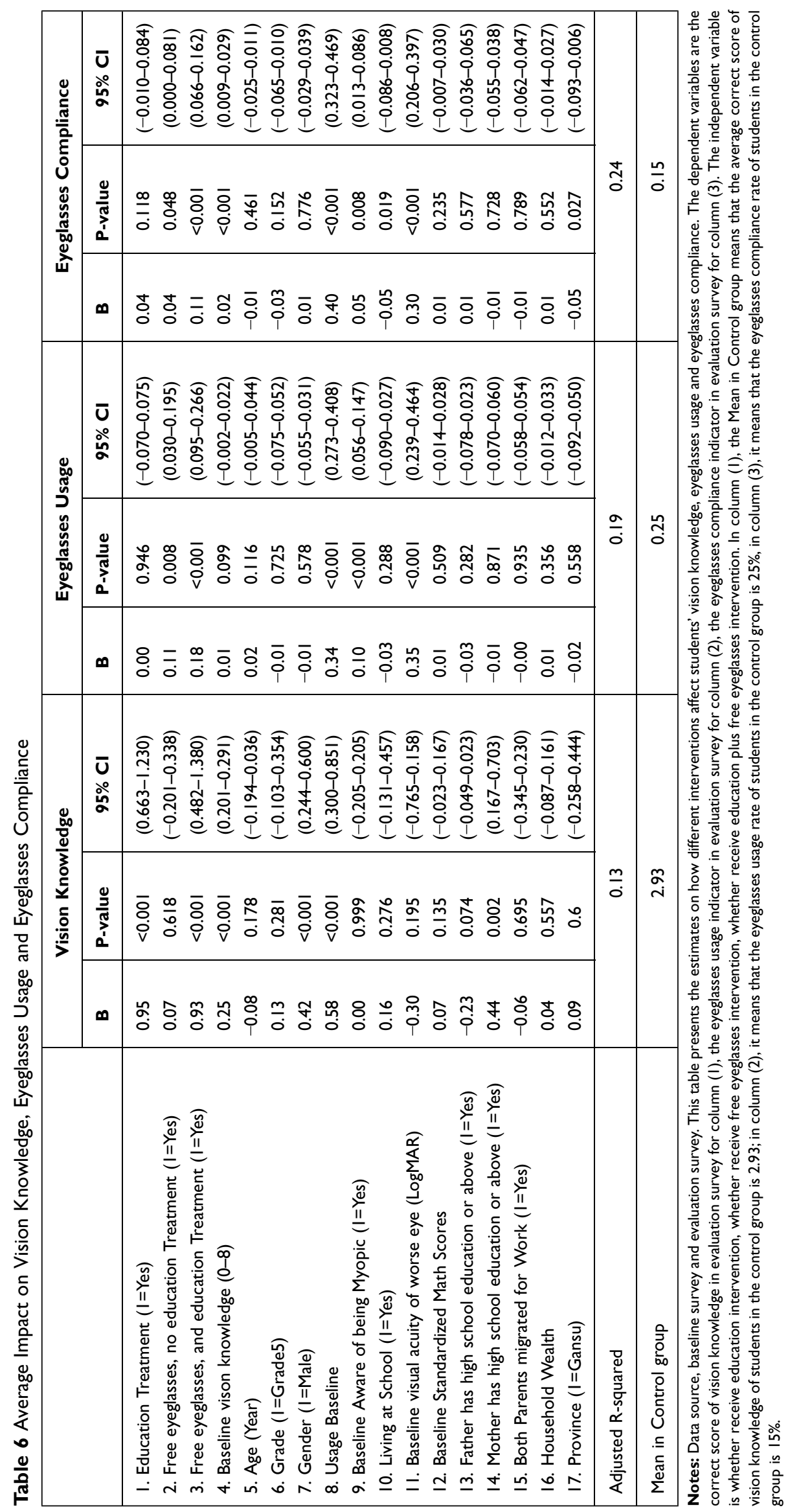


without necessary corresponding education, students will not wear the eyeglasses even if they get them for free and they have no chance of learning the benefits of eyeglasses.

Our findings not only confirm the work done by others on the complementarity of information and subsidy and the importance of subsidies in rural areas, but also reveal the role of the difference between the two in designing cost-effective health-care policies. This paper finds that the marginal effect of subsidy, when paired with information, is greater than only providing information or subsidy. It shows that accurate health information and subsidies can be used as a supplement to intervention design to improve health-care uptake and health outcomes.

From the earlier studies, it is obvious that correcting myopia in time can improve a student's academic outcomes, ${ }^{7}$ and the cost of uncorrected vision due to compromised quality of life and productivity far outweigh the cost of providing vision health education and subsidized vision care. From a policy perspective, this paper suggests that in-school vision health education and the subsidization of eyeglasses are important driving forces for the acceptance and wearing of eyeglasses. Social planners should reasonably consider expanding interventions combining health-care subsidies and health education to boost demand and build habits of using the health products which people previously underestimated the benefits of, and to cover other aspects of primary health care, prevention of infectious diseases, and chronic disease treatment.

\section{Acknowledgments}

The authors thank the support of the National Natural Science Foundation of China (Grant no. 71803107), and higher education discipline innovation project (Grant no. B16031). We also thank Luxottica Corporation, Essilor Corporation, CLSA Investment Brokerage and private donors for their financial and technical support, which do not have award/grant numbers. We would also like to thank Matthew Boswell, Fei He, Wenting Liu and the 300 enumerators from the Center for Chinese Agricultural Policy at the Chinese Academy of Sciences; Renmin University of China; Northwest University; and Shaanxi Normal University for their hard work. Special thanks to the staff from Zhongshan Ophthalmic Center at Sun Yat-sen University for their invaluable guidance and suggestions.

\section{Disclosure}

The authors report no conflicts of interest in this work.

\section{References}

1. He M, Huang W, Zheng Y, et al. Refractive error and visual impairment in school children in rural Southern China. Ophthalmology. 2007;114(2):374-382.e1. doi:10.1016/j.ophtha.2006.08.020

2. Congdon N, Wang Y, Song Y, et al. Visual disability, visual function, and myopia among rural Chinese secondary school children: the Xichang pediatric refractive error study (X-PRES)-report 1. Invest Ophthalmol Vis Sci. 2008;49(7):2888-2894. doi:10.1167/iovs.07-1160

3. Ma X, Zhou Z, Yi H, et al. Effect of providing free glasses on children's educational outcomes in China: cluster randomized controlled trial. BMJ. 2014;349(sep237):g5740-g5740. doi:10.1136/bmj. g5740

4. Krumholtz I. Results from a pediatric vision screening and its ability to predict academic performance. Optometry. 2000;71(7):426-430.

5. Atkinson J, Anker S, Nardini M, et al. Infant vision screening predicts failures on motor and cognitive tests up to school age. Strabismus. 2002;10(3):187-198. doi:10.1076/stra.10.3.187.8125

6. Williams WR, Latif AH, Hannington L, et al. Hyperopia and educational attainment in a primary school cohort. Arch Dis Child. 2005;90 (2):150-153. doi:10.1136/adc.2003.046755

7. Roch-Levecq AC, Brody BL, Thomas RG, et al. Ametropia, preschoolers' cognitive abilities, and effects of spectacle correction. Arch Ophthalmol. 2008;126(2):252-258. doi:10.1001/archophthalmol.20 07.36

8. PMC E. Sight test and glasses could dramatically improve the lives of 150 million people with poor vision. Indian J Med Sci. 2006;60 (11):485-486. doi:10.1007/s00107-011-0556-9

9. Bourne RR, Dineen BP, Huq DM, et al. Correction of refractive error in the adult population of Bangladesh: meeting the unmet need. Invest Ophthalmol Vis Sci. 2004;45(2):410-417. doi:10.1167/iovs. 03-0129

10. Ramke J, Du RT, Palagyi A, et al. Correction of refractive error and presbyopia in timor-leste. Br J Ophthalmol. 2007;91(7):860-866. doi:10.1136/bjo.2006.110502

11. Yi H, Zhang L, Ma X, et al. Poor vision among China's rural primary school students: prevalence, correlates and consequences. China Econ Rev. 2015;33:247-262. doi:10.1016/j.chieco.2015.01.004

12. Li L, Lam J, Lu Y, et al. Attitudes of students, parents, and teachers toward glasses use in rural China. Arch Ophthalmol Chic Ill 1960. 2010;128(6):759-765. doi:10.1001/archophthalmol.2010.73

13. Bai Y, Yi H, Zhang L, et al. An investigation of vision problems and the vision care system in rural China. Southeast Asian J Trop Med Public Health. 2014;45(6):1464-1473.

14. Guan H, Wang H, Du K, et al. The effect of providing free eyeglasses on children's mental health outcomes in China: a cluster-randomized controlled trial. Int J Env Res Public Health. 2018;15:2749. doi:10.33 90/ijerph15122749

15. Li F, Loyalka $\mathrm{P}$, Yi $\mathrm{H}$, et al. Ability tracking and social trust in China's rural secondary school system. Sch Eff Sch Improv. 2018;29:545-572. doi:10.1080/09243453.2018.1480498

16. Li L, Song Y, Liu X, et al. Spectacle acceptance among secondary school students in rural China: the Xichang pediatric refractive error study (X-PRES)-report 5. Invest Ophthalmol Vis Sci. 2008;49 (7):2895-2902. doi:10.1167/iovs.07-1531

17. Odedra N, Wedner SH, Shigongo ZS, et al. Barriers to spectacle use in Tanzanian secondary school students. Ophthalmic Epidemiol. 2008;15(6):410-417. doi:10.1080/09286580802399094

18. Wedner S, Masanja H, Bowman R, et al. Two strategies for correcting refractive errors in school students in Tanzania: randomised comparison, with implications for screening programmes. Br J Ophthalmol. 2008;92(1):19-24. doi:10.1136/bjo.2007.119198 
19. Hecht R, Shah R. Recent Trends and Innovations in Development Assistance for Health. Washington, DC: World Bank; 2006.

20. Nugent R, Knaul F. Fiscal Policies for Health Promotion and Disease Prevention. Washington, DC: World Bank; 2006.

21. Dupas P Do teenagers respond to HIV risk information? Evidence from a field experiment in Kenya. NBER Working Paper 14707. National Bureau of Economic Research, Inc; 2009.

22. Dupas P. What matters (and what does not) in households' decision to invest in malaria prevention? Am Econ Rev. 2009;99(2):224-230. doi:10.1257/aer.99.2.224

23. Kremer M, Miguel E. The Illusion of Sustainability. Social Science Electronic Publishing; 2004. doi:10.2139/ssrn.1111721

24. Rhee M, Sissoko M, Perry S, et al. Use of insecti- cide-treated nets (ITNs) following a malaria education intervention in Piron, Mali: a control trial with systematic allocation of household. Malar J. 2005;4(1):35. doi:10.1186/1475-2875-4-35

25. Black JM, Ausherman JA, Kandakai TL, et al. Urban university students' knowledge of alcohol and drinking. Am J Health Stud. 2004;19(2):91-99.

26. Rivera B. The effects of public health spending on self-assessed health status: an ordered probit model. Appl Econ. 2001;33 (10):1313-1319. doi:10.1080/00036840010007146

27. Shi Y, Nie W, Mu M, et al. What can children learn from a free trial of eyeglasses use? Evidence from a cluster-randomized controlled trial in rural China. J Health Care Organ Provis Financ. 2020;57: 0046958020968776

28. Jalan J, Somanathan E. The importance of being informed: experimental evidence on demand for environmental quality. J Dev Econ. 2008;87(1):14-28. doi:10.1016/j.jdeveco.2007.10.002

29. Luoto J, Levine D, Albert J, et al. Nudging to use: achieving safe water behaviors in Kenya and Bangladesh. $J$ Dev Econ. 2014;110:13-21. doi:10.1016/j.jdeveco.2014.02.010

30. Ashraf N, Berry J, Shapiro JM. Can higher prices stimulate product use? Evidence from a field experiment in Zambia. Am Econ Rev. 2010;100:2383-2413.
31. Cohen J, Dupas P. Free Distribution or Cost-Sharing? Evidence from a Malaria Prevention Experiment. Cambridge: National Bureau of Economic Research; 2008. doi:10.1111/j.14680106.2009.00494.x

32. Meredith J, Robinson J, Walker S, Wydick B. Keeping the doctor away: experimental evidence on investment in preventative health products. $J$ Dev Econ. 2013;105:196-210. doi:10.1016/j.jdeveco.20 13.08.003

33. Dupas P. Getting essential health products to their end users: subsidize, but how much? Science. 2014;345(6202):1279-1281. doi: $10.1126 /$ science. 1256973

34. Dupas P. Short-run subsidies and long-run adoption of new health products: evidence from a field experiment. Econom J Econom Soc. 2014;82(1):197-228. doi:10.3982/ECTA9508

35. Wang H, Yang C, He F, et al. Mental health and dropout behavior: a cross-sectional study of junior high students in northwest rural China. Int $J$ Educ Dev. 2015;41:1-12. doi:10.1016/j. ijedudev.2014.12.005

36. Congdon N, Li L, Zhang M, et al. Randomized, controlled trial of an educational intervention to promote spectacle use in rural China: the see well to learn well study. Ophthalmology. 2011;118(12): 2343-2350. doi:10.1016/j.ophtha.2011.06.016

37. Luoto J, Mahmud M, Albert J, et al. Learning to dislike safe water products: results from a randomized controlled trial of the effects of direct and peer experience on willingness to pay. Environ Sci Technol. 2012;46(11):6244-6251. doi:10.1021/es2027967

38. Sylvia S, Ma X, Shi Y, et al. Ordeal mechanisms, information, and the cost-effectiveness of subsidies: evidence from subsidized eyeglasses in rural China. arXiv Preprint arXiv:1812 00383. 2018.

39. Kremer M, Glennerster R. Chapter four - improving health in developing countries: evidence from randomized evaluations. In: Handbook of Health Economics. Vol. 2. Elsevier; 2011:201-315.
Risk Management and Healthcare Policy

\section{Publish your work in this journal}

Risk Management and Healthcare Policy is an international, peerreviewed, open access journal focusing on all aspects of public health, policy, and preventative measures to promote good health and improve morbidity and mortality in the population. The journal welcomes submitted papers covering original research, basic science, clinical \& epidemiological studies, reviews and evaluations, guidelines, expert opinion and commentary, case reports and extended reports. The manuscript management system is completely online and includes a very quick and fair peer-review system, which is all easy to use. Visit http://www.dovepress.com/testimonials.php to read real quotes from published authors. 